International Journal of Social Science and Economic Research

ISSN: 2455-8834

Volume:06, Issue:01 "January 2021"

\title{
AN APPRAISAL OF NIGER STATE AGRICULTURAL SECTOR'S MEDIUM TERM SECTOR STRATEGY (MTSS), 2016-2018
}

\author{
YUNUSA Abdullahi \\ National Institute for Legislative and Democratic Studies, Abuja, Nigeria \\ DOI: 10.46609/IJSSER.2021.v06i01.013 URL: https://doi.org/10.46609/IJSSER.2021.v06i01.013
}

\begin{abstract}
The Niger state government has a vision to be among the top three most developed state in Nigeria by year 2020. This vision is encapsulated in the Niger state Vision 3:2020. The state government hope to achieve this Vision through harnessing her agricultural potential to address the development challenges of the state, especially in the areas of food security, unemployment and the high poverty incidence in the state. This goal was to be achieved through the agricultural sector's Medium term Sector Strategy (MTSS). This study therefore seek to ascertain the ways in which the Niger state agricultural sector's MTSS, 2016-2018, has addressed the development challenges of the state. The study is an empirical study, which collected evidence using quantitative research techniques. The quantitative research method adopted for this study is the survey research. Findings of the study revealed that the Niger state agricultural sector's MTSS, 2016-2018, had a positive effect on the agricultural sector of Niger state, as it was able to achieve most of its objectives with the exception of poverty reduction in the state. The study thus recommend that subsequent agricultural development programs should focus on post-harvest management of the agricultural sector with the objective of increasing the incomes of farmers and other producers in the agricultural value chain of Niger state, in order to address the poverty incidence in the state. To this end, the Niger State Commodity and Export Promotion Agency (NSCEPA) Act 2010 should be reviewed to empower the Agency to play significant role in this regard.
\end{abstract}

Keywords: Agricultural development program, agricultural policy, Niger state agriculture, Agricultural planning, post-harvest management

\section{Introduction}

Niger state is among the 36 federating states of Nigeria, situated in the north-central geo-political zone of the country. It is the largest state in terms of land mass, which is about 10 percent of the total land area of Nigeria (National Bureau of Statistics [NBS], 2010).About 85 percent of this land is arable and has one of the best soil types that have better water holding capacity and little erosion hazards. The state is endowed with eight big rivers, namely rivers Niger, Kaduna, 


\section{International Journal of Social Science and Economic Research}

ISSN: $2455-8834$

Volume:06, Issue:01 "January 2021"

Gbako, Eko, Gurara, Ebba, Chanchaga and Mariga. This is in addition to Kainji, Shiroro and Jebba lakes as well as the Niger flood plain (Niger State Bureau of Statistics [NSBS], 2012).

Niger state is endowed with an agricultural sector that has an excellent potential. The fertility of the soil and favorable climatic condition of the state permits the cultivation of both food and cash crops in commercial quantity, and still allows opportunity for grazing, fishing and forestry. Thus, in order to optimize this agricultural potential, the state government in partnership with other agricultural stakeholders, has initiated several agricultural development programs to develop the agricultural sector for optimum performance.

Unfortunately, despite the vast agricultural potentials of Niger state and the various approaches adopted to improve productivity of the sector, statistics as at 2016 showed that the state ranks poorly in most indices of a viable state. One would have expected that because of her aforementioned potentials, the state should rank among the top three most developed states in Nigeria in line with the State's Vision 3:2020. However, reverse seems to regrettably be the case, going by the disturbing level of high poverty rate, unemployment and low Internally Generated Revenue (IGR) of the state.

As at year 2016, 56.8 percent of Niger state populations were living below the poverty line of USD \$1 per day (Oxford Poverty \& Human Development Initiative [OPHI] Report, 2016). The state was also among the three states that were worst hit by unemployment in Nigeria, with 39.4 percent unemployment rate, placing her third place ahead of Bauchi and Zamfara states that occupies second and first positions respectively (NBS, 2016). Available statistics further revealed that the state was among the fourteen states with the poorest IGR of less than 10 percent in Nigeria. This meant that the state cannot survive without the monthly disbursement from the Federation Account Allocation Committee (FAAC). The state government therefore sought to address these development challenges by repositioning the agricultural sector as a driver of sustainable economic growth through food security, poverty reduction and job creation. This goal was to be achieved through the agricultural sector's Medium Term Sector Strategy (MTSS).

The agricultural sector's MTSS was first prepared in 2013 to run for a three year period of 2014 to 2016. However, it was rolled over in 2015 to reflect the policy changes of the All Progressive Congress (APC) led government, which took over from the People's Democratic Party (PDP) on $29^{\text {th }}$ of May, 2015. The rolled over MTSS was also to run for a period of three years, 2016 to 2018. One of the primary objective of the MTSS rollover was to develop the agricultural sector to facilitate the implementation of Niger state Vision 3:2020, which centers on the state's desire to be among the top three most developed states in Nigeria by year 2020. Specifically, it was hoped that by 2018 the MTSS rollover should have successfully managed the state's agricultural 


\section{International Journal of Social Science and Economic Research}

ISSN: $2455-8834$

Volume:06, Issue:01 "January 2021"

sector for sustainable economic growth through food security, poverty reduction and job creation.

This study therefore seeks to ascertain the ways in which the Niger state agricultural sector's MTSS, 2016 to 2018, have addressed the development challenges of the state. Specifically, this study will answer the research question: "what are the ways in which the Niger state agricultural sector's MTSS, 2016 to 2018, have addressed the development challenges of the state?

\section{2, Literature Review}

Several empirical studies have been carried out to examine the effects of agricultural development programs, strategies and policies on agricultural productivity. For instance, Ugwu and Kanu (2011) examined the effects of agricultural reforms on the agricultural sector of Nigeria. The study adopted desk study method, thus data were collected largely from secondary sources. The study analyzed several agricultural reform programs pursued by successive governments in Nigeria over a period of three decades. The authors reported that the various reforms have had unsatisfactory effect on agricultural productivity in Nigeria. This they attributed to poor performance of the reforms due to policy instability, poor coordination of policies, poor implementation and mismanagement of policy instrument, lack of transparency and high rate of corruption.

Agreeing with Ugwu and Kanu (2011), other scholars like Olayemi (1995), Olomola (1998) and Garba (1998) all provided evidence that showed that agricultural development programs in Nigeria have had minimal impact on agricultural productivity. Although these studies have different titles, their findings and conclusion were closely related. For instance, Olayemi (1995) titled his article "Agricultural policies for sustainable development: Nigeria's experience"; Olomola (1998) titled his paper "Analysis and management of agricultural sector performance and inter-sectional linkages"; while Garba (1998) titled his study "An analysis of the implementation and stability of Nigerian agricultural policies, 1970-1993". Using different research methodology, the authors concluded that agricultural development programs, strategies and policies have had minimal impact on agricultural productivity due to decreasing rural infrastructure, declining value of total credit to agriculture, and declining domestic and foreign investment in the sector.

On his path, Adebayo (2004) argued in his study titled "Rural development Nigeriana: Episodic drama, soap opera and comedy", that most of the agricultural development programs failed because the programs lacked in-depth studies and realistic pilot surveys. He further added that other contributing factors to the programs failure include lack of public participation in the design, formulation, implementation and evaluation of the programs. This is in addition to poor 


\section{International Journal of Social Science and Economic Research}

ISSN: $2455-8834$

Volume:06, Issue:01 "January 2021"

understanding of the details and specifics of the programs by the implementing ministries and agencies.

Obayelu and Okoruwa (2005) examined economic reforms on Nigeria agricultural sector using indicators such as GDP, food prices index, prices of agricultural inputs, effect on poverty and quality of agricultural products. The study used secondary sources to collect data on economic reforms from the pre-colonial era to the return to democratic rule in 1999. The findings of the study showed that there was no honesty on the path of policy implementers. The authors therefore argued that economic reforms in Nigeria's agricultural sector could only achieve the desired outcome of food security and economic growth only if the Nigerian government is honest in the execution of reform exercise.

Daneji (2011) in his study titled "Agricultural development intervention programs in Nigeria (1960 to date): A review", examined agricultural development programs and policies and the challenges they faced. The findings of the study showed that some of the agricultural development strategies adopted had positive impact on the agricultural sector. This findings agree with that of Wudir (1991), titled "Cereals in the food economy of Nigeria". The study reported that there was significant increase in rice and maize production which became manifest from 1989, consequent upon state intervention through quality research and introduction of improved technology.

Within the same period, other studies showed that research and research institutions, especially the International Institute for Tropical Agriculture (IITA), were making tremendous contribution to the improvement of food production in Nigeria. IITA (1992) revealed that the output of its research activities resulted in the production of about 13.2 million tonnes of cassava tubers in Nigeria in 1989. Around the same period, Omenesa (1991), in his study titled "The effect of radio on agricultural development in northern states of Nigeria", also reported that annual production of sorghum continued to increase due to improved varieties developed by researchers. The study further revealed that land under sorghum production increased from 0.5 million hectares in 1959 to over 3 million hectares in 1989, with a total production of over 3 million tonnes. Daneji (2011) concluded thus that the growth in the agricultural output in the late 1980s is traceable to policy and agency based development initiatives of successive governments. He however argued that lack of continuity and inconsistency in policy intervention by subsequent governments has been the greatest challenge to guaranteed self-sufficiency in food and fiber in Nigeria.

Along a similar line of thought, Ayoade (1978) in his PhD dissertation titled "Returns to investment in cocoa research in Nigeria", submitted to Faculty of Agriculture and Forestry, University of Ibadan, examined the organization of agriculture research technology in Nigeria 


\section{International Journal of Social Science and Economic Research}

ISSN: $2455-8834$

Volume:06, Issue:01 "January 2021"

and its impact on agricultural productivity. The findings of the study showed that there was a phenomenal increase in cocoa output over the years, which is linked to the introduction of improved varieties and control of pests and diseases. The study therefore recommended that scientific and technological research have crucial significance in addressing the low level of agricultural productivity in many third world countries.

For Nwojiuba (2013) the shortcomings of the agricultural policies lie in the policies themselves. He examined the Nigeria's agricultural and food security challenges alongside state-level intervention in the agricultural sector. The author argued that the wide range of policies, programs and projects have had limited impact in ameliorating the challenges in the agricultural sector. He further noted that in spite of the multiple policies and programs there is still a large rural population in need of agricultural policy support with a development focus. He therefore suggested that in designing future policy, consideration should be given to the emerging challenges of population growth and climate change. Furthermore, that there is a need for policy reform on inputs supply, technology improvement, and credit and subsidies. This is in addition to the need for a program focusing on the new generation of farmers, especially young educated farmers that will train them on agricultural entrepreneurship and provide them with both financial and technological support.

Eze Christopher et al (2010) examined the agricultural financing policies of Nigerian government and its effect on rural development. The study found that government made serious efforts at making sound agricultural policies through schemes, programs and institutions. Unfortunately, they were not back up with adequate budgetary allocation and financing, coupled with corruption in the implementation of the programs. The study therefore concluded that government efforts over the years in formulating good agricultural financial policies meant to encourage food production have been found inefficient and ineffective. Since the intended results were not realized. However, a similar study by Central Bank of Nigeria [CBN] (2007) on the same subject matter gave contrary findings.

CBN (2007) in her report titled "Agricultural Credit Guarantee Scheme Fund of Nigeria (ACGSF): An impact assessment", claim that agricultural finance have positive impact on farm income. The report argues that total average farm income generated by ACGSF beneficiaries was larger than that generated by non-beneficiaries. The report further claim that the ACGSF had a positive impact on employment in all the states studied and that the technical impact on beneficiaries are greater than for non-beneficiaries, particularly in term of enterprise expansion and land use. Hence, the report concluded that the positive impact of the scheme have helped in rural development. 
International Journal of Social Science and Economic Research

ISSN: 2455-8834

Volume:06, Issue:01 "January 2021"

Igudia (2017) carried out a qualitative analysis of the agricultural policy dynamics and the Nigerian economy, covering the period 1960 to 2015. The researcher argued that there have been avalanche of laudable agricultural policies that could turn Nigeria into an industrialized economy and reduce the incidence of poverty. Unfortunately, earlier attempts underperformed due principally to ineffective implementation and complete abandonment of such policies. The result therefore was a fall in foreign exchange earnings, low GDP level and lack of sectorial linkages. The study therefore recommends the need to redirect attention to a tactical and strategic agricultural model that will ensure there are linkages between agriculture and the other sectors of the economy both forward and backward linkages. That such a policy will make it possible for Nigeria to attain her Vision 20:2020, and thus fulfil her desire to be among the top 20 most developed economies in the world by year 2020 .

\section{Methodology}

\subsection{Research Design}

This study is an empirical research which collected verifiable evidence using quantitative research techniques. The quantitative research method adopted for this study is the survey research. To conduct the survey research we administer questionnaires that have predetermined set of both closed and opened questions. The research design therefore involved direct acquisition of relevant data from the field.

\subsection{Population, Sample and Sampling Technique}

The population of this study is the people of Niger state that falls within the age bracket of 15 to 69 years. However, because it was not possible to contact all the individual members of the population size in this type of study, a sample of the population size was therefore involved in the study. This sample of the study enabled us to make references, deduction and generalization of the entire population.

The sample for this study was drawn from the population size and spread across the three senatorial districts of Niger state. For the purpose of cost-effectiveness and overcoming time constraints, we selected one local government area (LGA)in each senatorial district to represent the zone. Using purposive sampling technique, we selected Lavun LGA for Niger-South senatorial district, Paikoro LGA for Niger-East senatorial district, and Wushishi LGA for NigerNorth senatorial district. The sample of the study therefore, from these three LGAs based on the National Population Commission (NPC) 2006 census result, considering the study's criteria that focus on people within the age bracket of 15 to 69 years, was 220,394 (Source: Author's calculation drawn from NPC 2006 census result). However, owing to practical limitations of 
International Journal of Social Science and Economic Research

ISSN: 2455-8834

Volume:06, Issue:01 "January 2021"

time and finance, it was not possible to get responses from 220,394 people. Thus, the Taro Yamane (1967) formula was used to arrive at a meaningful sample size of 400 respondents.

The sampling technique that was adopted for this study is the probability/random sampling technique. The probability research methods that we employed in the selection of our sample was the cluster sampling and purposive sampling. Thus, using the multiple stages sampling, our study population was divided into multiple clusters and then these clusters were further divided and grouped into strata (i.e. various sub groups) based on geographical location. After which one strata was selected to represent the cluster. In our first stage of sampling, therefore, we divided Niger state into three clusters based on senatorial districts. The second stage is we used stratified sampling to group the communities within the senatorial district (cluster) into LGAs (strata). The LGAs within the cluster represented the cluster (senatorial district). The next stage was for us to select one LGA (strata) from the three clusters to represent the clusters in our study. The final stage was the selection of households from the LGAs, using the systematic selection of 10 households per residential neighborhood.

\subsection{Technique for Data Analysis}

The study employed both descriptive and inferential statistics method to analyze the data obtained from both primary and secondary sources. The quantitative data from the questionnaire was analyzed and presented using frequency distribution tables and simple percentages, for easy and quick comprehension.

\section{Results and Discussion}

\subsection{Response Rate}

The researcher administered 400 questionnaires across the three (3) Local Government Area (LGAs) selected for the study, out of which 379 questionnaires were returned. However only 371 out of the 379 questionnaires returned were valid and useful because 8 questionnaires were returned unanswered, thus 371 stands as our response rate. The response rate to questionnaire administered for this study is therefore 92.8 percent. All the target respondents selected for this study responded well to the questionnaire administered. This was because of the personal contact and persuasion on the part of the researcher and three research assistants recruited from the host communities, one per selected LGA.

4.2 What are the ways in which the Niger State Agricultural Sector's Medium Term Sector Strategy (MTSS) Rollover, 2016-2018, has addressed the development challenges of the state? 
International Journal of Social Science and Economic Research

ISSN: 2455-8834

Volume:06, Issue:01 "January 2021"

Table 4.1: "Do you agree that Niger state government supported farmersin their agricultural activities, within 2016 to 2018?"

\begin{tabular}{|l|c|c|}
\hline \multicolumn{1}{|c|}{ Opinion } & Frequency & Percentage (\%) \\
\hline Agree & 196 & $52.8 \%$ \\
\hline Strongly Agree & 44 & $11.9 \%$ \\
\hline Neutral & 33 & $8.9 \%$ \\
\hline Disagree & 55 & $14.8 \%$ \\
\hline Strongly Disagree & 43 & $11.6 \%$ \\
\hline Total & $\mathbf{3 7 1}$ & $\mathbf{1 0 0 \%}$ \\
\hline
\end{tabular}

Source: Field Survey, October 2019

The key strategic direction of the Niger state agricultural sector MTSS, 2016-2018, is centered on supporting farmers in various forms in order to increase productivity. Table 4.1 reveals that 52.8 percent of the respondents agree that farmers in Niger state received support from the state government in their agricultural activities within 2016 to 2018, while 11.9 percent strongly agree with this position. Thus, majority of the respondents agree that farmers received some form of support within the period under study.

Table 4.2: "If you agree with question 1 above, what type of support have they received?"

\begin{tabular}{|l|c|c|}
\hline \multicolumn{1}{|c|}{ Options } & Frequency & Percentage (\%) \\
\hline $\begin{array}{l}\text { Farm inputs (e.g. fertilizer, improved } \\
\text { seedlings, agrochemicals, etc.) }\end{array}$ & 164 & $44.2 \%$ \\
\hline Financial support (loan, grant, etc.) & 142 & $38.3 \%$ \\
\hline Training & 76 & $20.5 \%$ \\
\hline Farming equipment & 22 & $5.9 \%$ \\
\hline I don't know & 131 & $35.3 \%$ \\
\hline
\end{tabular}

Source: Field Survey, October 2019 
Respondents were further asked to choose from a list of items what type of support farmers received within the period under study. They however selected multiple options because they believe that the type of support received by farmers is a combination of the choices provided. Table 4.2 shows that 44.2 percent of the respondents reveal that farmers were supported with farm inputs, such as fertilizer, improved seedlings and agrochemicals, among others. 38.3 percent of the respondents confirmed that farmers received financial support, 20.5 percent admit that farmers were trained on farming techniques, while 5.9 percent of the respondents asserted that farmers were supported with farming equipment.

Table 4.3: "Do you agree that Niger State farmers recorded increased output from their farms in 2018 farming season?"

\begin{tabular}{|l|c|c|}
\hline \multicolumn{1}{|c|}{ Opinion } & Frequency & Percentage (\%) \\
\hline Agree & 185 & $49.9 \%$ \\
\hline Strongly Agree & 55 & $14.8 \%$ \\
\hline Neutral & 98 & $26.4 \%$ \\
\hline Disagree & 22 & $5.9 \%$ \\
\hline Strongly Disagree & 11 & $3 \%$ \\
\hline Total & $\mathbf{3 7 1}$ & $\mathbf{1 0 0 \%}$ \\
\hline
\end{tabular}

Source: Field Survey, October 2019

The MTSS, 2016-2018, provided various type of support to farmers with the aim of increasing production output, especially in crop, livestock and fishery production in order to ensure food security. It was expected that by 31 December 2018 there should be increased yield and availability of food and cash crops, increased livestock population of quality animals and increased fish production and availability to consumers. To ascertain the extent to which this objectives were met, Table 4.3 shows that 49.9 percent of the respondents agree that Niger state farmers recorded increased output from their farms in 2018 farming season, while 14.8 percent strongly agree with this position. Thus majority of the respondents agree that there was increased production output in 2018 farming season.

True to the above assertion, the Niger state crop production figures 2014-2018,obtained from Niger State Agricultural and Mechanization Development Authority [NAMDA] (2018), shows 
increased yield and availability of food and cash crops in 2018 as against the baseline year of 2016, just as envisioned by the MTSS. The record shows that maize production increased from average yield of 3.0 metric tons(MT)/hectares(HA) in 2016 to 3.6MT/HA in 2018; rice production increased from average yield of 5.3 MT/HA in 2016 to $6.4 \mathrm{MT} / \mathrm{HA}$ in 2018; sorghum production increased from 2.2 MT/HA in 2016 to $2.7 \mathrm{MT} / \mathrm{HA}$ in 2018; cassava production increased from $35 \mathrm{MT} / \mathrm{HA}$ in 2016 to $42.4 \mathrm{MT} / \mathrm{HA}$ in 2018; yam production increased from 25.5 MT/HA in 2016 to $30.9 \mathrm{MT} / \mathrm{HA}$ in 2018; while groundnut production increased from 2.8 MT/HA in 2016 to 3.4 MT/HA 2018. Similarly, NAMDA (2018) also revealed that there was increased livestock population of quality animals in 2018 as against the baseline year of 2016. Number of cattle produced increased from 2,429,075 in 2016 to 2,577,006 in 2018; number of goat produced increased from 2,821,649 in 2016 to 2,993,486 in 2018; while the number of sheep produced increased from 2,576,290 in 2016 to 2,733,186 in 2018. Similarly, the number of poultry produced increased from 7,665,841 in 2016 to $8,132,690$ in 2018 . On the contrary, fish production declined successively from 2016 through 2017 and 2018. The number of fish produced decreased with more than half from 113.5 metric tons in 2016 to 44.5 metric tons in 2017 and further declined to 39.6 metric tons in 2018. This declined was attributed to various flooding episode experienced in the state within the period under study.

Table 4.4: "If you agree with question 3 above, what do you think is responsible for the increased output?"

\begin{tabular}{|l|c|c|}
\hline \multicolumn{1}{|c|}{ Options } & Frequency & Percentage (\%) \\
\hline Support from state government & 120 & $32.3 \%$ \\
\hline Adoption of modern method of farming & 131 & $35.3 \%$ \\
\hline Adequate rainfall/favorable climate condition & 98 & $26.4 \%$ \\
\hline Increase access to finance/loan & 120 & $32.3 \%$ \\
\hline I don't know & 47 & $12.7 \%$ \\
\hline
\end{tabular}

Source: Field Survey, October 2019

This study went further to investigate the factors that are responsible for the increase in production output of the agricultural sector of Niger state. Respondents were given a list of options of the likely reason for the increase in production output. Most of them however, selected multiple choices from the options provided because they believe multiple factors are 
International Journal of Social Science and Economic Research

ISSN: 2455-8834

Volume:06, Issue:01 "January 2021"

responsible for the increased output in production. Table 4.4 shows that 35.3 percent of the respondents believe that the increase in production output is due to adoption of modern method of farming. 32.3 percent of the respondents asserted that it is due to support from government and increased access to finance, while 26.4 percent opined that it is due to adequate rainfall/favorable climate condition.

Table 4.5: "Do you agree that irrigation/dry season farming is adequately practice in Niger State?"

\begin{tabular}{|l|c|c|}
\hline \multicolumn{1}{|c|}{ Opinion } & Frequency & Percentage (\%) \\
\hline Agree & 229 & $61.7 \%$ \\
\hline Strongly Agree & 76 & $20.5 \%$ \\
\hline Neutral & 33 & $8.9 \%$ \\
\hline Disagree & 22 & $5.9 \%$ \\
\hline Strongly Disagree & 11 & $3 \%$ \\
\hline Total & $\mathbf{3 7 1}$ & $\mathbf{1 0 0 \%}$ \\
\hline
\end{tabular}

Source: Field Survey, October 2019

The MTSS, 2016-2018,also sought to encourage and intensify irrigation practices in Niger state, in order to minimize dependence on rainwater for farming. The objective is to facilitate all year round agricultural production. Table 4.5 reveals that 61.7 percent of the respondents agree that irrigation/dry season farming is adequately practice in Niger state, while 20.5 percent of the respondents strongly agree with this position. This shows that majority of the respondents agree that there is increasing number of farmers practicing dry season farming in the state. The Agricultural Sector Baseline Performance Review Report 2013-2017, published in 2018, shows that the hectares of land cultivated under irrigation practices as at 2017 is 189.5 hectares of land. However, the Report (2018) noted that these were land area under irrigation through private efforts by farmers. The MTSS, 2016-2018, however, has as one of its objectives to cover 5000 hectares of land to be irrigated through government support by 2018, but as at the time of this study, data was not available to show the number of land under irrigation through government support. 
International Journal of Social Science and Economic Research

ISSN: 2455-8834

Volume:06, Issue:01 "January 2021"

Table 4.6: "Do you agree that farmers in Niger State received any type of support from government towards irrigation/dry season farming within year 2016-2018?"

\begin{tabular}{|l|c|c|}
\hline \multicolumn{1}{|c|}{ Opinion } & Frequency & Percentage (\%) \\
\hline Agree & 145 & $39.1 \%$ \\
\hline Strongly Agree & 32 & $8.6 \%$ \\
\hline Neutral & 106 & $28.6 \%$ \\
\hline Disagree & 76 & 20.5 \\
\hline Strongly Disagree & 12 & $3.2 \%$ \\
\hline Total & $\mathbf{3 7 1}$ & $\mathbf{1 0 0 \%}$ \\
\hline
\end{tabular}

Source: Field Survey, October 2019

To get first-hand knowledge on Niger state government support towards irrigation farming in Niger state, respondents were asked if farmers received any type of support from the state government towards irrigation/dry season farming within 2016 to 2018. Table 4.6 reveals that 39.1 percent of the respondents agree that farmers in the state received support from government, while 8.6 percent strongly agree with this position. Since 28.6 percent of the respondents remained neutral on the issue, we may conclude that majority of the respondents agree that farmers in Niger state were supported by government to encourage and intensify irrigation/dry season farming in the state within the period under study.

One of the aims and objectives of the MTSS, 2016-2018, is to set out fully costed strategies and expenditure plan through which the agricultural sector seeks to contribute to the attainment of the long-term poverty reduction goal of Niger state government over the period 2016 to 2018. However, records from the Oxford Poverty and Human Development Initiative [OPHI] (2016, 2017, and 2018) shows that the multidimensional poverty index (MPI) in Niger state increased steadily from 0.303 in 2016 to 0.324 in 2017 and reached 0.364 in 2018. Similarly percentage of poor people living below USD $\$ 1$ per day in Niger state increased from 56.8 percent in 2016 to 61.2 percent in 2017 and reached 61.6 percent in 2018. Notwithstanding, the MTSS's goal of employment generation seems to have yielded positive result as the records of the National Bureau of Statistics [NBS] (2016, 2017 and 2018) shows that unemployment in Niger state 


\section{International Journal of Social Science and Economic Research}

ISSN: $2455-8834$

Volume:06, Issue:01 "January 2021"

reduced from 39.4 percent in 2016 to 10.6 percent in 2017 , but raised again to 20.9 percent in 2018.

This study thus found that in spite of the increased productivity of the agricultural sector of Niger state, poverty rate increased consistently during the MTSS, 2016-2018 period.The possible explanation for this is that although farmers and other producers in the agricultural value chain experienced increased production output, post-harvest product management was not coordinated in such a way to guarantee increased income to farmers.Immediately after harvest, the farmers and producers are desperate to sell their produce due to lack of adequate storage/processing facilitates, which create a situation of excess supply/market glut thus reducing the prices of these products. This is a typical example of the commodity market responding to the classical economic law of supply and demand.

The classical economic law of supply and demand argues that supply and demand pull against each other in a free market economy until the market reach an equilibrium price. The law statesthat in a situation where the supply of a commodity is higher than the demand of such commodity, the price is likely to reduce. On the contrary, if thedemand of a commodity is higher than the supply of such commodity, the price is likely to increase (Chappelow, 2019).Thus in Niger state,although farmers recorded bumper harvest within the period under review, they all tried to sell these products within the shortest period of time so that the products will not spoil before getting to the consumers. Unfortunately, this created a glut in the agricultural commodity market, thus the products did not earn them enough income that will lift them out of poverty.

The above assertion is further confirmed by the Nigeria's National Bureau of Statistics [NBS] 'Selected Food Prices Watch' (2019), which is a report of the average prices of agricultural products within January 2016 to March 2019. The report revealed that the average price of one dozen of agricultural eggs medium size decreased year-on-year by -12.80 percent and month-onmonth by -0.96 percent. Also, the average price of $1 \mathrm{~kg}$ of rice decreased year-on-year by -0.39 percent and decreased month-on-month by -0.68 percent. While the average price of $1 \mathrm{~kg}$ of yam tuber decreased year-on-year by -21.07 percent and month-on-month by -2.71 percent. The implication of this findings is that if post-harvest period is not properly managed, consistent glut in the agricultural commodity market on a year-on-year basis can trigger a vicious cycle of declining prices, lower profit and increase in poverty rate, thereby defeating the essence of the agricultural development programs.

\section{Conclusion}

This study sought to ascertain the ways in which the agricultural sector's MTSS, 2016-2018, have addressed the development challenges of Niger state; especially in areas of increased productivity of the agricultural sector for the purpose of food security, job creation and poverty 


\section{International Journal of Social Science and Economic Research}

ISSN: $2455-8834$

Volume:06, Issue:01 "January 2021"

reduction. The findings of the study revealed that the MTSS had a positive effect on agricultural productivity by improving the production output of crops and livestock. It alsoreduced unemployment rate in the state but was not able to reduce the poverty rate in the state. Thus one may argue that the Niger state agricultural sector's MTSS, 2016-2018, had a positive effect on the agricultural sector of Niger state, as it was able to achieve most of its objectiveswith the exception of poverty reduction in the state. This findings is consistent with the findings of Wudir (1991), Omenesa (1991), and Daneji (2011). The implication of this findings is that the current agricultural sector's MTSS rollover, 2019 to 2021, should focus on post-harvest management of the agricultural sector with the objective of increasing the incomes of farmers and other producers in the agricultural value chain of Niger state, in order to address the poverty incidence in the state.

\section{Recommendation}

I. Niger state government should intensify her efforts towards linking farmers with off-takers. The state government can also serve as off-taker through Niger State Commodity and Export Promotion Agency (NSCEPA). NSCEPA was assented into law in 2010 to develop the abundant agricultural commodities of the state for both domestic and international market. The agency need to be reviewed to go beyond linking farmers and actor in the agricultural value chain to market, to procuring agricultural commodities for buffer stock program and resell. Thus, the agency will need to maintain a standard conditioning centers, storage and processing facilities. The agency should also be empowered to establish and maintain a Shea butter refinery and Groundnut oil refinery and managed it in a similar way the Nigerian National Petroleum Corporation (NNPC) manage Nigeria's petroleum refinery. For effective service delivery and direct link with the stakeholders in the agriculture value chain the agency should be moved from its current Ministry of Investment, Commerce and Cooperation to Ministry of Agriculture and Rural Development. While the Ministry of Agriculture and Rural Development should be renamed 'Ministry of Agriculture, Rural Development and Poverty Reduction'. This will enable the ministry to coordinate all poverty reduction programs under the various agricultural development programs.

II. The current agricultural sector's MTSS rollover, 2019-2021, should focus on increasing farmers and other producers in the agricultural value chains earnings by linking them with off-takers. The government can achieve this objective by linking farmers with private large-scale processors, like flourmills, breweries, pharmaceuticals, and confectioneries, among others to off-take these produce at harvest. These off-takers can specify the type of produce they need so that government support to farmers will be geared towards ensuring they meet the off-taker's specification. 


\section{International Journal of Social Science and Economic Research}

ISSN: $2455-8834$

Volume:06, Issue:01 "January 2021"

\section{References}

Adebayo K (2004). Rural development Nigeriana: Episodic drama, soap opera and comedy. University of Agriculture Aberkuta Alumin Association Lecture Series No. 6 January 2004.

Ayoade (1978). "Returns to investment in cocoa research in Nigeria". PhD dissertation, Faculty of Agriculture and Forestry, University of Ibadan.

Central Bank of Nigeria/CeRAM, 2007. Agricultural Credit Guarantee Scheme Fund of Nigeria (ACGSF): An Impact Assessment. Study conducted by Centre for Resource Analysis and Management (CeRAM) for the Governing Board of the Agricultural Credit Guarantee Scheme Fund, Central Bank of Nigeria, February, 2007.

Chappelow, J. (2019). Law of supply.

Retrieved from https:/www.investopedia.com/terms///lawofsupply.asp

Daneji M (2011). Agricultural development intervention programs in Nigeria (1960 to date): A review. Savannah Journal of Agriculture 6(1):1-7.

Eze Christopher C, Lemchi J, Ugochukwu A I, Eze V, Awulonu C, Okon A (2010). Agricultural financing policies and rural development in Nigeria. Paper presented at the $84^{\text {th }}$ Annual Conference, March 29-31, 2010, Edinburgh, Scotland.

Garba PK (1998). "An Analysis of the Implementation and stability of Nigerian Agricultural Policies, 1970 - 1993 "Final report submitted to the African Economic Research Consortium (AERC), Nairobi, Kenya.

Igudia P. O (2017). A Qualitative Analysis of the Agricultural Policy Dynamics and the Nigerian Economy: 1960-2015. European Scientific Journal December 2017 edition Vol.13, No.34 ISSN: 1857 - 7881 (Print) e - ISSN 1857- 7431

International Institute of Tropical Agriculture (1992) IITA in the News, Ibadan, Jan-June edition p. 11.

National Bureau of Statistics (NBS) (2010). Nigeria Poverty Profile.

National Bureau of Statistics [NBS] (2019). 'Selected Food Prices Watch'.

Niger State Bureau of Statistics (NSBS), (2012). Niger State agricultural statistics: Fact and figures about Niger State. Retrieved from: www.nigerstats.ni.gov.ng. 
International Journal of Social Science and Economic Research

ISSN: 2455-8834

Volume:06, Issue:01 "January 2021"

Obayelu, A. E. and Okoruwa, V. O. (2005). "Economic reform in the Agricultural sector of Nigeria: Merits and Demerits," Development and Comp Systems 0509014, University library of Munich, Germany.

Olayemi JK (1995). “Agricultural Policies for Sustainable Development: Nigeria's Experience” in Ikpi A.E. and J.K. Olayemi (Ed). Sustainable Agriculture and Economic Development in Nigeria. Winrock International, 1995.

Olomola AS (1998). "Analysis and Management of Agricultural Sector Performance and Intersectional Linkages" Paper Presented at Training Programme on Sectoral Policy analysis and Management (NCEMA) June, 1998.

Omenesa, Z. E. (1991) "The Effect of Radio on Agricultural Development in the Northern States of Nigeria" in Lawani S.M. and T. Babalaye (eds). Proceedings of the Workshop on Recent Development in Cereal Production in Nigeria. Pp. 63-71.

Oxford Poverty and Human Development Initiative (2016), (2017), and (2018). "Nigeria Country Briefing”, Multidimensional Poverty Index Data Bank. OPHI, University of Oxford.

Oxford Poverty and Human Development Initiative (OPHI), Report 2016, 2017, and 2018.

Ugwu, D. S. and Kanu, I. O. (2011), Effects of agricultural reforms on the agricultural sector in Nigeria. Journal of African Studies and Development Vol. 4(2) Pp. 51-59.

Wudir, B. B. (1991) "Cereals in the Food Economy of Nigeria" in Lawani S.M. and T. Babaleye (eds). Proceedings of the Workshop on Recent Development in Cereal Production in Nigeria. Ibadan IITA 2-4 Sept. 1991 pp. 13-25. 